\title{
Transfer of Tuberculin Immunity from Mother to Infant
}

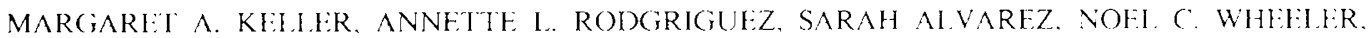 \\ AND IDIANE REISINGER

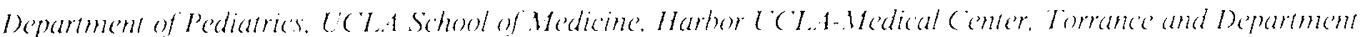

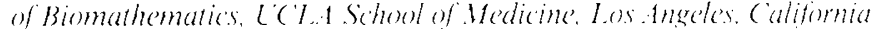

\begin{abstract}
ABSIRACI. The purpose of our study was to investigate transfer of tuberculin immunity from mother to infant via breast milk by studying newborn lymphocyte blastogenesis induced by purified protein derivative antigen at 1-5 days of age, 4-6 wk of age, and 3 months of age. Our study consisted of four mother-infant groups: breast-feeding and bottle-feeding infants of tuberculin-positive and tuberculinnegative mothers. $\Lambda$ difference in the groups was found only at 4-6 wk of age where $17 \%(4 / 23)$ of breast-feeding infants and $13 \%(2 / 15)$ of bottle-feeding infants of tuberculin positive mothers had lymphocyte blastogenesis to purified protein derivative. None of the infants of tuberculin negative mothers had purified protein derivative-induced blastogenesis. Analysis of covariance with tests for equality of slopes showed that the responses of tuberculin-positive mothers were significantly different from the responses of tuberculin-negative mothers $(p<0.05)$. These studies suggest transplacental transfer of tuberculin immunity evident at 4-6 wk of age which wanes by 3 months of age. We could not find evidence of transfer via human milk. (Pediatr Res 22: 277-281, 1987)
\end{abstract}

\section{Abbreviations}

PPl), purified protein derivative (Connaught)

IIBSS, I Ianks' balanced salt solution

PIIA, phytohemagglutinin

SI, stimulation index

cpm, counts per minute

III, heat inactivated

Previous investigators have suggested that transfer of tuberculin immunity may occur via human breast milk (1-3). Others have found evidence for transplacental transfer of tuberculin immunity (4), measles immunity (5) and cellular immunity to other infectious antigens (4).

Mohr's (1) study was based on tuberculin skin tests performed in 11 children of five tuberculin-positive mothers vears after birth. Five of the nine breast-feeding infants of tuberculin-positive mothers had positive tuberculin skin tests. The two infants that were not breast-fed had negative skin tests. As was suggested by the author, these preliminary results did not exclude transplacental transfer of tuberculin immunity. Environmental exposure can also not be excluded. Studies have examined in vitro lymphocyte blastogenesis to PPI) by studving lymphocvtes obtained from cord blood or neonatal blood. Both Schlessinger and Cov-

Received Decomber 12.1986: alecented April 2.1987.

(orrenondence and repuests for Harbor-

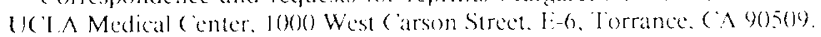

Supported by a contract from NICHI) V(OL-HI)-2-2815 and by NiH-(iCR( (irant RR()0425. elli's (3) study and the study of Ogra (' al. (2) found no evidence of cord blood lymphocyte response to PPD antigen hut did find PPD-induced blastogenesis responses for lymphocytes obtained from infants 4-5 wk of age. Since maternal PPI)-induced lymphocyte blastogenesis has been found to be depressed in the last 4 wh of pregnancy and at the time of delivery (6), it is possible that cord blood lymphocytes may not respond optimally in a blastogenesis assay. For this reason we chose to examine neonatat lymphocyte response instead of cord blood lymphocyte response to PPI).

The purpose of our study was to investigate transfer of tuberculin immunity via human breast milk by studying newborn lymphocyte blastogenesis induced by PPI) antigen at $1-5$ davs of age. 4-6 wk of age. and 3 months of age. In addition to blastogenesis we wished to study functional capability transfer from the mother to the infant as evidenced by lymphokine production. For this purpose. PPD-induced production of monocyte chemotactic factor was examined for neonatal ly mphocytes obtained at 4-6 wk of age. We chose this time for lymphokine studies since previous studies had shown transfer of a blastogenesis capability evident at $4-5$ wk of age.

We also wished to examine the mechanism of transfer of this cellular immunity. Transfer of lymphocutes from the mother to the infant either via the placenta or human milk must be considered. We studied male infants of tuberculin positive breastfeeding mothers at 4-6 wk of age. The sex of the dividing lymphocytes responding to PPD stimulation was examined.

\section{MFIHOISS}

Study population. Healthy postpantum adult females with known tuberculin status participated in the study with their healthy infants. Mothers were classified as tuberculin-positive or tuberculin-negative on the hasis of skin test results shortly after delivery, during pregnancy. or prior to pregnancy. Repeat skin testing was not done for tuberculin-positive mothers. For this study. a subject with $\geq 12 \mathrm{~mm}$ of induration at the skin test site after $48-72 \mathrm{~h}$ was defined as tuberculin positive. We purposely used such a large amount of induration to eliminate borderline readings. Tuberculin-negative subjects had no induration at the skin test site. Tuberculin-negative mothers were skin tested at time of entry into the study ( $1-5$ days postpartum) and again at the first return visit $4-6$ wk postpartum. All tuberculin negative mothers without confirmatory negative skin lesting at $4-6$ wk postpartum were excluded from the study since pregnancy and delivery have been associated with decreased tuberculin immunits (6). In addition, all tuberculin-negative mothers with a history of $B C(\mathrm{j}$ immunization were excluded from the study

Our study consisted of four mother-infant groups: infants of tuberculin-positive breast-feeding mothers, infants of tuberculinpositive bottle-feeding mothers. infants of tuberculin-negative breast-feeding mothers, and infants of tuberculin-negative bottle- 
feeding mothers. Mothers and infants were excluded if the infant had any serious illness in the first 3 months of life. Breast-feeding infants received at least $80 \%$ of their feeding as human breast milk. Bottle-feeding infants never received any human breast milk.

Informed consent was obtained from all mothers and this study was approved by the human subjects committee.

Lymphocyte studies. Infant lymphocytes from peripheral blood were examined at 1-5 days of age, 4-6 wk of age, and 3 months of age. The mean ages for the four groups (PPD + breastfeeding, PPD + bottle-feeding, PPD - breast-feeding, PPD bottle-feeding) were quite similar. At $1-5$ days, the mean ages ( \pm SE) were $1.5 \pm 0.1,1.3 \pm 0.1,1.9 \pm 0.5,1.6 \pm 0.2$ days. At $4-6$ wk the mean ages were $31.2 \pm 0.8,31.5 \pm 1.0,32.6 \pm 1.6,31.9$ \pm 1.5 days, and at 3 months the mean ages were $86.9 \pm 4.6,90.1$ $\pm 4.1,91.2 \pm 2.7,83.0 \pm 2.5$ days. Peripheral blood and colostrum/milk specimens were obtained from mothers at $1-5$ days postpartum and 4-6 wk postpartum.

Mononuclear cell isolation for Ivmphocyte cultures. Peripheral whole blood was diluted in HBSS, $\mathrm{Ca}++, \mathrm{Mg}++$ free, and the mononuclear cell fraction separated by Ficoll-Hypaque differential centrifugation (7). After washing, mononuclear cells were resuspended for counting in RPMI-1640, containing gentamicin $(10 \mu \mathrm{g} / \mathrm{ml})$ and an antibiotic-antimycotic preparation (Gibco) and additional $\mathrm{L}$-glutamine. Cell viability was determined using trypan blue exclusion and the differential calculated by staining cells with $0.025 \%$ methyl violet in $0.5 \%$ acetic acid. Breast milk cells were first centrifuged at $1400 \mathrm{RPM}(250 \times g)$ to remove the fatty top layer and washed twice in HBSS to eliminate additional fat. Lymphocytes were then harvested in the same manner as peripheral blood cells and counted using toluidine blue stain in a wet-preparation differential. When cell yield did not permit Ficoll-Hypaque separation, total washed milk cells were used.

Lymphocvte stimulation by PPD antigen. PPD $2 \mathrm{mg} / \mathrm{ml}$ concentrate was diluted with HBSS containing $0.1 \%$ fetal bovine serum (heat inactivated) to achieve the following final concentrations for lymphocyte cultures: $200,100,50,25,10,5,2.5,0.5$, $0.1,0.05, \mu \mathrm{g} / \mathrm{ml}$ PPD. Fifty $\mu \mathrm{l}$ of appropriate antigen dose was added to triplicate wells of a 96-well, U-bottom microtiter plate, (Linbro). In addition, a dose of $0.83 \mu \mathrm{g} / \mathrm{ml}$ final concentration of PHA (Burroughs Welcome) was also assayed as a control for culture viability. Lymphocytes were resuspended in RPMI-1640 containing $5 \%$ heat inactivated human $A B$ sera for a final concentration of $1 \times 10^{6}$ lymphocytes $/ \mathrm{ml} .1 \times 10^{5}$ lymphocytes were added to each well stimulated with antigen as well as nonstimulated control wells. Microtiter plate cultures were placed at $37^{\circ} \mathrm{C}, 5 \% \mathrm{CO}_{2}$ for 7 days. Additional lymphocyte cultures were also included for incubation periods of 3,5 , and 6 days when cell yield permitted. After incubation, cells were radiolabeled with ${ }^{3} \mathrm{H}$-thymidine (Amersham) and $0.4 \mu \mathrm{Ci}$ were added to each well. Twenty-four $h$ later, the cells were harvested onto glass fiber filter discs and upon addition of scintillant cocktail, counted in a liquid scintillation counter. SI was calculated by dividing the cpm from stimulated wells by the cpm from nonstimulated wells. The stimulated $\mathrm{cpm}$ minus the nonstimulated $\mathrm{cpm}$ was also calculated as $\Delta \mathrm{cpm}$. Maximum responses of infant lymphocytes at any dose at any time of culture harvest were used for data analysis.

Generation of lymphocyte-derived monocyte chemotactic factor. Lymphocyte cultures $\left(1 \times 10^{6}\right.$ lymphocytes $\left./ \mathrm{ml}\right)$ were incubated at $37^{\circ} \mathrm{C}$ with $5 \% \mathrm{CO}_{2}$ for $72 \mathrm{~h}$ in serum-free RPMI- 1640 with additional I-glutamine. Stimulated cultures were incubated with $10 \mu \mathrm{g} / \mathrm{ml}$ PPD antigen. Nonstimulated control cell cultures were incubated without antigen which was added at the end of the incubation period. Supernatants were harvested by centrifugation and frozen at $-70^{\circ} \mathrm{C}$ until assay.

Monocyte chemotaxis assay. Test supernatants from PPD stimulated and nonstimulated cultures were diluted $1: 2$ and $1: 3$ in RPMI-1640 and 5\% fetal bovine serum (HI) for assay. Each assay included a lymphocyte culture supernatant from a tuberculin positive adult control. Monocyte chemotaxis was assayed using the method of Altman et al. (8) and Snyderman et al. (9). Blind well chambers (Bio-Rad Laboratories) were used with upper and lower compartments separated by a $5.0 \mu \mathrm{m}$ Nucleopore filter. Human peripheral blood monocytes from adult laboratory volunteers were used as test monocytes and were prepared by Ficoll-Hypaque differential centrifugation. The wetpreparation differential was done using $0.025 \%$ methyl violet, and the mononuclear cells were suspended at a concentration of $1.5 \times 10^{6}$ monocytes $/ \mathrm{ml}$ in RPMI- 1640 with $5 \%$ fetal calf serum. For each chamber and filter, $0.2 \mathrm{ml}$ of monocyte resuspension, containing $1.5 \times 10^{6}$ monocytes $/ \mathrm{ml}$, was added to the top of the filter. Appropriate dilutions of test supernatants were placed in the lower chambers $(0.2 \mathrm{ml})$. The chemotaxis chambers were then incubated for 90 minutes at $37^{\circ} \mathrm{C}$ with $5 \% \mathrm{CO}_{2}$. To measure chemotactic activity, the filters were removed at the end of the incubation period, fixed in ethanol, and stained in hemotoxylin and Wright's stain. Under oil immersion, the average number of monocytes per field migrating to the opposite side of the filter was determined by counting 20 fields for each filter. Each supernatant dilution was assayed in triplicate. Chemotactic activity was calculated by comparing the monocyte migration in nonstimulated supernatants to those stimulated by PPD. The number of monocytes migrating toward stimulated supernatants minus the number of monocytes migrating toward control supernatants was used as $\Delta$ migrating monocytes.

Statistical methods. To investigate the effect of breast-feeding status on lymphocyte blastogenesis, several approaches were used. In one approach infants were classified as lymphocyte blastogenesis responders if they satisfied a definition based on cutpoints for SI and $\Delta \mathrm{cpm}$ and on comparison of stimulated and nonstimulated counts. A positive monocyte response was defined by a cutpoint for $\Delta$ monocytes. To determine the cutpoints for SI, $\Delta$ cpm and $\Delta$ monocytes, we determined with $99 \%$ confidence tolerance limits between which will lie $99 \%$ of infant responses from tuberculin-negative mothers (10). The upper tolerance limit was then used as a cutpoint to define positive and negative responses. These tolerance limit cutpoints varied for the three time periods at which infants were studied: $\Delta \mathrm{cpm} \geq 6325$, SI $\geq 3.6$ at entry; $\Delta \mathrm{cpm} \geq 3613 \mathrm{SI} \geq 3.1$ at $4-6 \mathrm{wk}$ of age, $\Delta$ $\mathrm{cpm} \geq 3261$, SI $\geq 2.9$ at 3 months of age. An infant was considered to have a positive lymphocyte blastogenic response if tolerance limit criteria were met for either SI or $\Delta \mathrm{cpm}$. Also, the cpm in stimulated wells had to be statistically significantly different from the counts per minute in control wells using Student's $t$ test on logarithmically transformed data (11). Tolerance limit criteria were also used to analyze $\Delta$ monocytes for monocyte chemotactic factor and a $\Delta$ monocytes $\geq 18.9$ was considered to be a positive response. In both blastogenesis and monocyte chemotaxis assays, Fisher's exact test (12) was used to compare breast and bottle feeders for percent of positive responders. This was done for infants of PPD-positive mothers separately from infants of PPD-negative mothers to determine effect of feeding method on results. In addition, infants of tuberculin-positive breast-feeding mothers were compared to infants of tuberculin-negative breast-feeding mothers. Similar comparisons were performed on bottle-feeding infants.

In another statistical approach, SI and $\Delta \mathrm{cpm}$ data were logarithm transformed and a two-way analysis of variance (13) was used to determine if there were significant effects of feeding, tuberculin status, or interaction of these on blastogenesis data at each time period. When the analysis of variance indicated a significant effect of tuberculin status or feeding, the Bonferroni approach to controlling the overall level of significance at 0.05 was used to do six pairwise comparisons (each at $\alpha$ of 0.008 ).

Another statistical approach consisted of two-way analysis of covariance on stimulated counts with nonstimulated counts as a covariate (13). Correlation analysis was used to investigate the linear relation between stimulated and nonstimulated counts. 
Chromosome analisis. I ymphocytes from male infants (4-6) wk of age) were cultured with PPD) or without antigen for 7 days. Colcimid treatment was used to arrest cells in metaphase and standard air-dried chromosome preparations were made.. (hromosome analyses, primarily for sex chromosome constitutions were performed with the aid of Q-banding.

\section{RISSUITS}

L.mphocte hlestogenesis. Table 1 summarizes the data in terms of infants meeting tolerance limit criteria for SI and $J \mathrm{cpm}$ in addition to having $\mathrm{cpm}$ statistically significantly $(\mathrm{p}<0.05)$ different in stimulated and nonstimulated wells. $\wedge t 4-6$ wh of age, $17 \%$ of infants of tuberculin-positive breast-feeding mothers and $1.3 \%$ of infants of tuberculin-positive bottle-feeding mothers had lymphocyte blastogenesis to PPI). One of the breast-feeding infants of a tuberculin-positive mother with a positive response at 4-6 wh of age had also had a positive blastogenie response at age $1-5$ days. One of the bottle-feeding infants of a tuberculinpositive mother with a positive response at 4-6 wk of age also continued to have a positive response at 3 months of age. When Fisher's exact test (12) was used to compare the number of responders in each of the four groups at each of the times studied. there were no statistically significant differences. However. if all infants of tuberculin-positive mothers were compared to all infants of tuberculin-negative mothers at 4-6 wk regardless of feeding method, the number of responders $6 / 38$ (16\%) rersus $0 /$ $33(0 \%)$ was statistically significantly different $(p<0 .(0)$ ). Table 2 presents the mean stimulation index and mean $\lrcorner$ epm for each of the four groups at each of the study times.

For analysis. SI and $\perp$ cpm data were transformed logarithmically $s o$ as $t o$ satisfy better the assumption of equal variances in the four groups. $A$ two-way analysis of variance showed that at 4-6 wh of age there was a significant effect of both mother's PPI) status and feeding method on SI and $J \mathrm{cpm}$ data. The interaction of PPI) status and feeding method was not significant. U Ise of the Bonferonni pairwise test showed that this difference was between the infants of PPI)-positive breast-feeding mothers and infants of PPI) negative bottle-feeding mothers. These results were not helpful in determining the influence of breast-fecding versus bottle-feeding on transferred immunity. Analysis of variance revealed no effect of feeding or PPI) status on Si or $J$ cpm at $1-5$ days of age. At 3 months of age. there was no significant effect of PPI) status or leeding on $\lrcorner \mathrm{cpm}$. but there was a significant interaction for the SI data. Thus. one cannot make any conclusion about effect of feeding or PPI) on SI. The

Table 1. Infemts with positive limphorlte hlestogenesis to Pl'l)

$$
\text { Age } 1-5 \text { days }
$$

(1)efinition of responder: $S \mathrm{SI} \geq 3.6$. or $\mathrm{J}$ (pm $\geq 6.325 .7 \leq 0.05)$

$$
\begin{gathered}
\text { Infants of PPI)-positive } \\
\text { mothers }
\end{gathered}
$$

Breast-feeding Bottle-feceding Breast-feeding Bottle-feeding

$$
2 / 3.3(6 \%) \quad 0 / 26(0 \%) \quad 1 / 24(4 \%) \quad 0 / 14(0 \%)
$$

Age 4-6 wk

(1) finition of responder: $\mathrm{SI} \geq 3.1$. or $د$ (p)m $\geq 361.3 . p \leq 0.05$ )

$$
\begin{gathered}
\text { Infants of PPI -positive } \\
\text { mothers }
\end{gathered}
$$

Breast-feeding Bottle-feeding Breast-feeding Botte-feeding

$$
4 / 23(17 \%) \quad 2 / 15(13 \%) \quad 0 / 19(0 \%) \quad 0 / 14(0 \%)
$$

Age $3 \mathrm{mo}$

(Definition of responder: $\mathrm{SI} \geq 2.9$. or $\mathrm{Acpm} \geq 3261 . P \leq 0.05)$

\begin{tabular}{|c|c|c|c|c|}
\hline & \multicolumn{4}{|c|}{ Mean stimulation index $( \pm$ SF: } \\
\hline & $\begin{array}{l}\text { PPI)+ } \\
\text { mother }\end{array}$ & $\begin{array}{l}\text { PPID+ } \\
\text { mother }\end{array}$ & $\begin{array}{l}\text { PPI)- } \\
\text { mother }\end{array}$ & $\begin{array}{l}\text { PPI)- } \\
\text { mother }\end{array}$ \\
\hline Age & breast-feceding & bottle-feeding & breast-fecding & bottle-feeding \\
\hline $1-5$ days & $\begin{array}{l}1.9 \pm 0.2 \\
(n=33)\end{array}$ & $\begin{array}{l}1.5 \pm 0.1 \\
(n=26)\end{array}$ & $\begin{array}{l}1.5 \pm 0.1 \\
(n=24)\end{array}$ & $\begin{array}{l}1.7 \pm 0.2 \\
(n=14)\end{array}$ \\
\hline $4-6 w k$ & $\begin{array}{l}1.9 \pm 0.1 \\
(n=23)\end{array}$ & $\begin{array}{l}1.6 \pm 0.1 \\
(n=15)\end{array}$ & $\begin{array}{l}1.6 \pm 0.1 \\
(n=19)\end{array}$ & $\begin{array}{l}1.3 \pm 0.1 \\
(11=14)\end{array}$ \\
\hline \multirow[t]{2}{*}{$3 \mathrm{mo}$} & $\begin{array}{l}1.6 \pm 0.1 \\
(n=12)\end{array}$ & $\begin{array}{l}1.9 \pm(0.2 \\
(n=9)\end{array}$ & $\begin{array}{l}1.5 \pm 0.1 \\
(n=14)\end{array}$ & $\begin{array}{l}1.2 \pm 0.1 \\
(n=9)\end{array}$ \\
\hline & \multicolumn{4}{|c|}{ Mean $د$ cpm $( \pm S H)$} \\
\hline $1-5$ days & $\begin{array}{l}1293 \pm 361 \\
(n=33)\end{array}$ & $\begin{array}{l}707 \pm 19 ! \\
(n=26)\end{array}$ & $\begin{array}{l}1212 \pm 367 \\
(n=24)\end{array}$ & $\begin{array}{l}717+176 \\
(11-14)\end{array}$ \\
\hline $4-6 w k$ & $\begin{array}{c}238(0 \pm 692 \\
(n=23)\end{array}$ & $\begin{array}{c}1.377 \pm 505 \\
(n=15)\end{array}$ & $\begin{array}{l}16 \pm 196 \\
(n=19)\end{array}$ & $\begin{array}{l}221 \pm 155 \\
(n=14)\end{array}$ \\
\hline $3 \mathrm{mo}$ & $\begin{array}{l}660 \pm 433 \\
(n=12)\end{array}$ & $\begin{array}{l}591 \pm 252 \\
(n=9)\end{array}$ & $\begin{array}{l}721 \pm 210 \\
(11=14)\end{array}$ & $\begin{array}{l}14 \pm 51 \\
(n=9)\end{array}$ \\
\hline
\end{tabular}

$$
\begin{gathered}
\text { Infants of PPI -positive } \\
\text { mothers }
\end{gathered}
$$

Breast-fieding Bottle-feeding

$0 / 12(0 \%)$
Infants of PPI)-negative mothers

Breast-feeding Bottle-fecding $0 / 14(0 \%) \quad(0 / 9)(0 \%)$

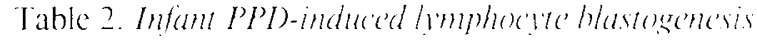

correlation analysis showed a strong dependence of stimulated counts on nonstimulated counts. The linear regression analysis for stimulated epm versus nonstimulated cpm for all the different groups studied showed slopes ranging from 0.81 to 2.20. The Pearson correlation coefficient (14) was always $>0.84$ with $p<$ 0.00005

Analysis of covariance (14) was performed on the stimulated cpm (as the dependent variable) with the nonstimulated cpm as a covariate. The est for equality of slopes of the regression of stimulated $\mathrm{cpm}$ on nonstimulated epm at both $1-5$ days and 3 months of age showed no significant difference in the slopes for any of the feeding or PPI) groups. Analysis of covariance showed no effect of feeding or PPD group in the blastogenesis results at $1-5$ days or 3 months of age.

The data at $4-6$ wh of age are strikingly different. When the atsumption of equality of slopes in the four groups was tested for the analysis of covariance. the hypothesis of equal stopes was rejected $(p<0.05)$. These results are summariad graphically in Figure 1. The stopes (stimulated versus nonstimulated (p) for for PPI) positive brast-feeding infants remus PPI)-positive bonkfeeding infants did not differ. Similarly, the slopes for PPI)negative breast-feceding and PPD-negative botte-feeding intants did not differ. However. each positive group differed from each negative group $(p<0 .(0)(05)$. The test for equality of stopes suggests strongly that the transter of tubereulin immunity from mother to infant evident at $4-6$ wh of age is transplacental. not via human breast milk.

Matemal limphorge hlavengenesis. Mothers were classitied as tuberculin positive or negative based on shin test, but blastogenesis data correlated well with skin test results. I incar regression analysis was performed to determine if there was any correlation between babyes $\mathrm{SI}$ or $\perp$ epm and mother's $\mathrm{SI}$ or $\perp \mathrm{cpm}$. The strongest correlation was for the PPD + bottk-feeding group. The corretation coefficient for SI (haby at $4-6$ wh rersus SI (mother 4-6 wk postpartum) was $(0.82(j)<0.005)$. Ihe corresponding correlation coefficient for PPI) + brast-feeding mothers was only $r=0.03$.

lilk dalu. Analysis of covariance was performed on milk stimulated epm with nonstimulated cpm as a covariate. There was no effect of maternal PPI) status on the human milk PPI)induced blastogenesis probably due to the wide variability in the cpm. The mean ( \pm SF) SI for milk lymphocytes from PPI) + mothers was $2.7( \pm 1.1)$. The mean ( \pm SF) for PPI)-mothers was $1.8( \pm 0.4)$.

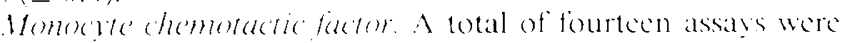
performed on supernatants from PPI)-stimulated Iymphocyte cultures from infants $4-6$ wk of age. In each assay specimens 


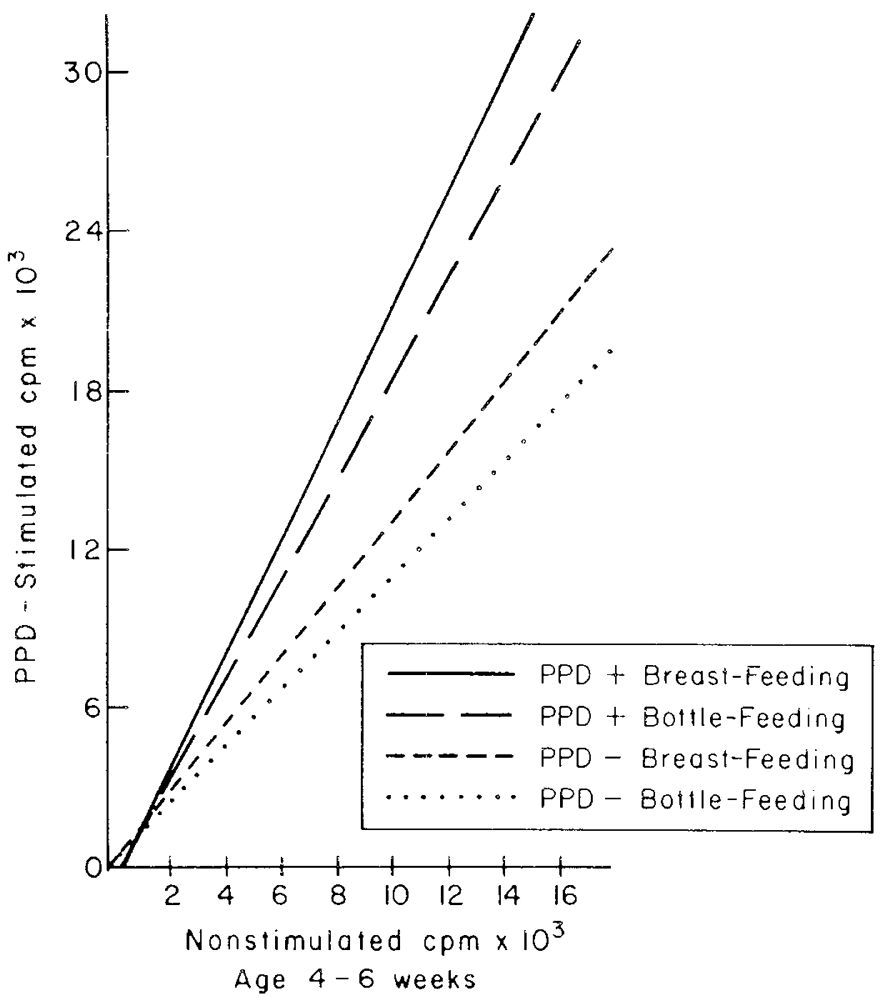

Fig. 1. Cpm for PPD-stimulated cultures versus $\mathrm{cpm}$ for control cultures for each of four groups studied at 4-6 wk of age.

from infants of both tuberculin-negative and tuberculin-positive mothers were assayed to control for variability of the assay. $\Delta$ monocytes for specimens obtained from infants of tuberculinnegative mothers was used to determine with $99 \%$ confidence the tolerance limit below which $99 \%$ of negative values $(\Delta$ monocytes) should fall. This tolerance limit cutpoint ( $\Delta$ monocytes $\geq 18.9$ ) was used to define a positive response.

Two of $17(12 \%)$ infants of breast-feeding tuberculin-positive mothers had positive results for PPD-induced lymphokine production while one of $11(9 \%)$ infants of tuberculin-positive bottle feeding infants were also positive. None of the 14 infants of tuberculin-negative breast-feeding or three infants of tuberculinnegative bottle-feeding mothers had evidence of lymphokine production. These results might also suggest transplacental transfer of tuberculin immunity since the PPD + breast-feeding and PPD + bottle-feeding infant groups are not significantly different (12 versus $9 \%$ ), but the response rate of the tuberculin-positive groups are not significantly different from the tuberculin-negative control groups.

Of the three infants with lymphokine production, none had been defined as a responder in the blastogenesis assay performed at the same time. There did not appear to be much correlation between the two assays although the results are similar in suggesting transplacental transfer.

Chromosome data. Two male infants with PPD-induced lymphocyte blastogenesis had metaphase spreads analyzed for the sex of the dividing cells. All 179 and 132 metaphase spreads examined from these infants were male (XY) suggesting that transferred maternal cells are not responsible for the blastogenesis.

\section{DISCUSSION}

The main purpose of our study was to determine if tuberculin immunity can be transferred from the mother to the infant via human breast milk. If we could demonstrate an effect of mother's tuberculin status on tuberculin immunity in the infant and no effect of feeding method, we would conclude that transfer occurred via the placenta. If both mother's tuberculin status and method of feeding influenced results, transplacental transfer and transfer via milk must be considered.

We first analyzed the lymphocyte blastogenesis data using the traditional SI and $\Delta \mathrm{cpm}$. We used strict tolerance limit criteria to define a positive response in both blastogenesis and monocyte chemotaxis assays and analyzed the number of positive responders in each group using Fisher's exact test. This analysis allowed no firm conclusion about transplacental versus milk transfer and only suggested transplacental transfer.

We then analyzed the data using the traditional analysis of variance with SI or $\Delta \mathrm{cpm}$ as the variable studied. At 4-6 wk there was evidence of a significant effect of PPD status and feeding group on the lymphocyte blastogenesis. Unfortunately, the difference was between the infants of PPD-positive breastfeeding mothers and the bottle-feeding infants of PPD-negative mothers. This result was not helpful in dissecting transplacental versus milk transfer of immunity. Again, we were left with no clear answer. Since our correlation analysis showed a strong dependence of stimulated cpm on nonstimulated cpm, we used another statistical approach, the two-way analysis of covariance on stimulated counts with nonstimulated counts as a covariate. In order to perform analysis of covariance, the slopes (stimulated $\mathrm{cpm}$ versus nonstimulated $\mathrm{cpm}$ ) must be equal. At $1-5$ days and 3 months of age, the assumption of equality of slopes was satisfied and the analysis of covariance did not show any effect of PPD status or feeding group on lymphocyte blastogenesis. When the data were examined at 4-6 wk of age, the assumption of equality of slopes was not satisfied. Hence, analysis of covariance could not be done. The slopes for stimulated cpm versus nonstimulated $\mathrm{cpm}$ in Figure 1 are quite striking in that the slope for PPDpositive breast-feeding infants did not differ from that of PPDpositive bottle-feeding infants. Similarly, the slopes for PPDnegative breast-feeding and PPD-negative bottle-feeding infants did not differ. However, each positive group differed from each negative group. For a given nonstimulated $\mathrm{cpm}$, the stimulated cpm was determined solely by the tuberculin status of the mother. The feeding method had no effect. These results suggest strongly that the transfer of tuberculin immunity from mother to infant evident at $4-6$ wk of age is transplacental, not via human breast milk.

In addition, this transplacental transfer of immunity appears to be transient since it wanes between 4-6 wk and 3 months of age. This disappearance of transferred immunity agrees with the previous studies of Ogra et al. (2) and Pabst et al. (4). Presumably, the lack of evidence for transferred immunity at 1-5 days of age is the result of immunoincompetence of the neonate or residual effects from the stress of delivery. However, Shiratsuchi and Tsuyuguchi (15) have demonstrated cord blood lymphocyte blastogenesis to PPD in specimens from infants of tuberculin-positive mothers, suggesting transplacental transfer of immunity.

Most difficult is to reconcile our results with those of Schlessinger and Covelli (3) since their prospective study showed an effect of breast-feeding on transfer of tuberculin immunity. This was evidenced at $4 \mathrm{wk}$ of age when eight of 13 infants of PPDpositive breast-feeding mothers had a stimulation index $\geq 2.0$ for PPD-induced blastogenesis. Only one of 13 infants of PPDpositive bottle-feeding mothers and none of nine infants of PPDnegative breast-feeding mothers met similar criteria. In Schlessinger and Covelli's (3) study, the mean nonstimulated cpm for the breast-feeding negative control group at age $4 \mathrm{wk}(16,449)$ was higher than the nonstimulated cpm for the breast-feeding-positive group (3751) and bottle-feeding-positive group (2759). We also found a pattern of higher nonstimulated cpm's in breastfeeding infants at 1-5 days, 4-6 wk, and 3 months of age compared to bottle-feeding infants but did not find such large differences between the groups. The large differences in the nonstimulated cpm of the previous data may have influenced the results. We are very comfortable with our analysis of cova- 
riance and tests of equality of stopes since the dependence of stimulated cpm on nonstimulated cpm is considered.

Recently, Stephens at al. (16) showed that breast-fed infants have higher spontaneous proliferation than bottle-fed infants at age 6 days and 6 wh of age. but by age 6 months spontaneous proliferation was higher in bottle-fed than breast-fed infants. Transfer of immunologically active factors in the milk were proposed as an explanation for the higher results in breast-leeding infants of young age. Older bottle-feeding infants may have higher nonstimulated counts due to a higher antigenic exposure via the gastrointestinal tract. Whatever the reasons for these observed immunologic differences between breast-feeding and bottle-feeding infants, our study does not show a difference in transfer of immunity to a specific antigen such as PPI) between breast-feeding and bottle-feeding infants.

Another difference between our study and the previous study (3) is the number of patients and the inclusion of a PPI)-negative bottle-feeding group in the control groups. At 4-6 wh of age our study included 38 infants of tuberculin-positive mothers and 33 infants of tuberculin-negative mothers compared to 26 infants of tuberculin-positive mothers and nine infants of tuberculinnegative mothers in the previous study. This sample size difference, particularly in control groups. may also explain our different conclusions.

A confounding variable that may influence our results is the ethnicity of the population studied. Our population is largely an indigent population with many Mexican- $\wedge$ merican mothers participating in the study. The percentage of Mexican- $A$ merican women in the tuberculin-positive groups was higher $(90 \%)$ than in the tuberculin-negative groups (27\%). However. if such a difference influenced our results, it did not affect results at 1-5 days or 3 months of age. Another possible confounding variable could be sex differences in the infant groups. This was not a factor for our study since the male-female ratio was similar in the four groups.

Our results agree with studies of other authors suggesting transplacental transfer of cell-mediated immunity. (iallager 't al. (5) found cord blood lymphocyte blastogenesis to measles antigen in six of 12 infants of seropositive mothers. Unlike our study. this study showed persistence of this blastogenesis for several months in a few infants. Thong of al. (17) examined rubella cytotoxicity in 11 newborn cord specimens and found positive results from three infants. Russell (18) examined cord blood lymphocyte blastogenesis to PPI in infants of mothers with a positive PPI)-induced lymphocyte blastogenesis. (One of the five such infants studied had a positive lymphocyte blastogenic response. He also showed that two of 14 infants of mothers responding to herpes virus antigen were positive for blastogenesis to herpes antigen.

Other investigators have examined antigen-stimulated lymphokine production as an index of transplacental transfer of cellular immunity from the mother to the infant. Field and Caspary (19) demonstrated production of a PPI-induced macrophage inhibition factor in infants of tuberculin positive mothers. Pabst $2 t$ al. (4) have also shown production of lymphokine in infants of mothers with reactivity to several antigens. In our study, it was interesting that the infants with production of lymphokine did not respond with blastogenesis. However. this additional assessment of transfer of immunity also suggested transplacental transfer.

Our work does not answer the mechanism of transfer. Both transfer of lymphocytes from mother to fetus across the placenta during pregnancy or at the time of delivery and transfer of subcellular factors from mother to infant such as lymphokines are possibilities. We tried to examine transfer of maternal cells but our study was not adequate to eliminate this possibility. One cannot rule out transfer of maternal cells which are eliminated from the infant quickly but persist as subcellular factors. Transter of maternal lymphocetes mav occur rarely to infants $(20-22)$. However, it is clear that maternal cells are not the cells responding to the PPI) with blastogenesis. Antigen cxposure in urew has been shown in both mouse and human systems (23) to influence the cellular immune response of the developing felus. He beliewe that this is an unlikely possibility for our study since all subjects were in good health and did not have or had not had active tuberculosis.

In summary our study clearly supports the hypothesis that cellular immunity to PPD antigen as evidenced by blastogenesis and lymphokine production is transferred from the mother to her infant. We find no evidence to suggest a role for breast milk in this transfer, but find clear evidence for transplacental transfer of tuberculin immunity.

Akmowledgments. The authors thank T. K. Mohandas. Ph. I). Division of Medical (ienetics. Harbor-LC A Medical center. for chromosome studies, and Ruth Williams and Joy Heiner for secretarial assistance.

\section{RIETHREVC HS}

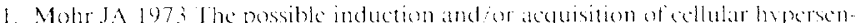
sitivity associated with ingestion of colostrum. I Pediatr $\$$ :2:1062 I004

2. Ogra SS. Weintrauh D). Ogra PI 197\% Immunologic aspects of human colestrum and milk 1IJ. Fate and absorption of cellular and soluhle componemes in the gastrointestinal tract of the newhorn. J lmmunol 114:245-24s

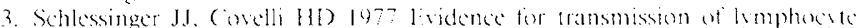
responses to tuberculin by breast-feceding. fancet $2: 529-532$

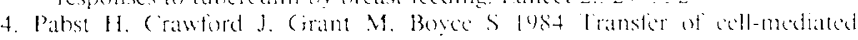
immunity (c) Mll to the letus. Pediatr Res $18: 2621$

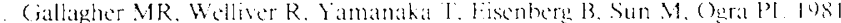

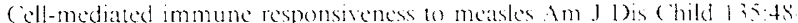
51

6. (ovelli HI). Wilson RT 1978 Immunologic and medical considerations in

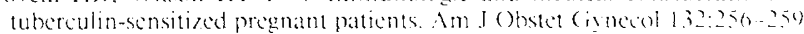

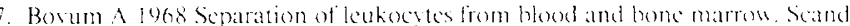
J L ab Invest 21:77

8. Alman I.C. Snyderman R. JU Oppenheim. Mergenhagen SF 1973 A human mononuckar leukocyte chematactic factor: characterization, specificity and kinctics of production of homologous keukocrtes. J Immunol 110:801 810

9. Snyderman R. Mcadows I Amos D) B 1977 (harackerization of human che-

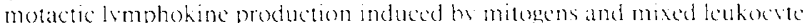
reaction in using a new microassay. (c)ll lmmunol $30: 225-2.5$

10. Dixon WJ. Massey FJ 198.3 Introduction to Statistical Analysis, the cat Meciaw-Hill Book (ompans. N) p p 152.583

11. Documenta (ieigy Scientific Tables oth ed. 1962 (icigs Phamacouticals Ardsley . 1Y, 32

12. Documenta (icigy Scientific Tathes oth ed 1962 (icigs Phamaceuticals. Ardsley, Ny, pp $109-123$

13. Veter J. Wasserman W 1974 Applied lincar Statistical Medels. Regression Analses of Variance. and fxperimental Designs. Irwin. Ine. Homewond. II.

14. Bever Whl (ed) Correlation coeflicient. In (Re Handbook of lables for Probability and Statistics anded. Ihe (hemical Rubber (o) (leveland. () I. p) $389-396$

15. Shimatsuchi H. Isuvuguchi I 1981 luberculin purilied protein deriative-

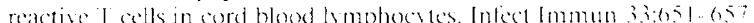

16. Stephens S. Brenner MK. Duti SH. lahhani PK. Kenneds ( $R$. Farrant 1980 The eflects of breast-fecding on proliferation by intan ly mphocytes m itro. Pediatr Res 20:227 231

17. Thong YH. Hurtade Re. Rola-Plesennshi M. Hernsen Si. Vincont MM MichelettiSA. Bellanti JA 1974 Transplacental transmisston of cell-mediated immunity. Iancet 1:1286-1287

18. Russell AS 1975 ( Dll-mediated immunity to microbial antigens in mother and child. (lin Fap Immunol 22:457-460)

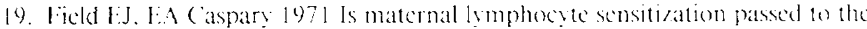
child? 1 ance $2.3 .37-3.1$

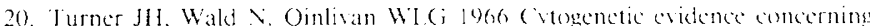
possible transplacental transfer of leukocyles in pregnant women. Am i Obstet (ivnecol $95: 8.31-8.33$

21. ()ding 1. 1972 The possibility of materno-foctal transfer of lymphoryes in man. Acta Pacdiatr Sand 61:73-75

22. Benirschke K. Sullivan MM 1969 the human placenta in relationship to the development of chimerism in the foeto-placental unit. In: Pecile A. Pinzic (eds) 1xcerpta Medicaf loundation. Amsterdam, pp 49-56

23. (iill III TJ. Repetti ( $F$. Metlay IA. Rabin BS. Taylor FH. Thompsen IDS Cartese AI. 1983 Transplacental immunization of the human fetus to tetanus by immunization of the mother. J (lin Invest 72:987-996) 